\title{
El tifo, la fiebre amarilla y la medicina en México durante la intervención francesa
}

\author{
Monserrat Gerardo-Ramírez', Jesús Zavaleta-Castro² y Luis Enrique Gómez-Quiroz ${ }^{1}$
}

${ }^{1}$ Departamento de Ciencias de la Salud, Universidad Autónoma Metropolitana Iztapalapa, Ciudad de México; '2Instituto Estatal de Documentación de Morelos, Cuernavaca, Mor., México

\begin{abstract}
Resumen
El periodo comprendido entre 1861 y 1867, marcado por la ocupación extranjera, particularmente por Francia, es sin lugar a dudas rico en gestas de patriotismo sin igual en la historia de México por la coyuntura política, militar e incluso religiosa del periodo en cuestión; sin embargo, poco se ha abordado de manera concreta el estado que guardaban la salud y la ciencia médica en dicho periodo, lleno de episodios sumamente interesantes en cuanto a epidemias como el tifo, la fiebre amarilla o el cólera, sobre todo cuando estas enfermedades afectaron y marcaron el rumbo de la historia nacional, a la par con el desarrollo de la naciente medicina científica mexicana encabezada por varios médicos, en especial por el Dr. Miguel Francisco Jiménez.
\end{abstract}

PALABRAS CLAVE: Tifo. Fiebre amarilla. Intervención francesa. General Zaragoza. Maximiliano de Habsburgo.

\begin{abstract}
French intervention in Mexico (1861-1867) is particularly full of episodes of patriotic heroism in terms of military, politic and, even, religious affairs, however this history is also rich in episodes related to diseases and the evolution of Mexican scientific medicine practice, epidemics such as typhus (nowadays knows as rickettsiosis), yellow fever, or cholera. Principally, this context outlined the Mexican history and influenced the course of the nation. The epidemics served as fertile land for the development of medicine science leading by prominent physicians, particularly by doctor Miguel Francisco Jiménez.
\end{abstract}

KEY WORDS: Typhus. Yellow fever. French intervention. General Zaragoza. Maximilian of Habsburg.

\author{
Correspondencia: \\ Luis E. Gómez-Quiroz \\ Departamento de Ciencias de la Salud \\ Universidad Autónoma Metropolitana Iztapalapa \\ Av. San Rafael Atlixco, 186 \\ Col. Vicentina, Del. Iztapalapa \\ C.P. 09340, Ciudad de México, México \\ E-mail: legq@xanum.uam.mx
}

Fecha de recepción en versión modificada: 02-11-2016

Fecha de aceptación: 02-11-2016

DOI://dx.doi.org/10.24875/GMM.17002811
Gac Med Mex. 2018;154:111-117

Contents available at PubMed www.gacetamedicademexico.com 


\section{Introducción}

«Inmensa, dolorosísima, tal vez irreparable es la pérdida que acaba de sufrir la República», expresó Francisco Zarco aquel sábado en el Panteón de San Fernando, ante la tumba de Ignacio Zaragoza. Cinco días antes, la mañana del 8 de septiembre de 1862, el héroe de la batalla del 5 de mayo había muerto a consecuencia del tifo. Después de su triunfo sobre las tropas francesas en Puebla, contrajo la enfermedad a su paso por las Cumbres de Acultzingo, donde había visitado a los soldados liberales heridos y enfermos. El General Zaragoza fue asistido por el médico Juan N. Navarro, enviado expresamente por el presidente Benito Juárez, y expiró ante su madre y una de sus hermanas'.

Cuatro meses antes, el 5 de mayo, Zaragoza había informado del triunfo del ejército mexicano sobre las fuerzas invasoras en Puebla. En el parte militar destacó «el comportamiento de mis valientes compañeros", pues "el hecho glorioso que acaba de tener lugar patentiza su brío, y por sí solo los recomienda» como patriotas. Al referirse al ejército francés reconoció que "se ha batido con mucha bizarría", a pesar de que «su general en jefe se ha portado con torpeza en el ataque" a la ciudad poblana. "Las armas nacionales [...] se han cubierto de gloria», concluyó Zaragoza ${ }^{2}$.

El periodo que abarca la intervención francesa, desde el desembarco de las tropas europeas (1861) hasta el fusilamiento de Maximiliano de Habsburgo (1867), es sin lugar a duda uno de los periodos más fascinantes en la historia del país. Más allá de la parte bélica y política, la presencia de varias enfermedades, como el tifo y la fiebre amarilla, moldearon a nuestra nación; irónicamente, es también un periodo en que la medicina mexicana se levanta con bases científicas gracias a la medicina francesa.

\section{El tifo}

El año anterior al inicio de la intervención francesa, Benito Juárez García, en su calidad de presidente de la República, había publicado el Decreto de Suspensión de la Deuda Extranjera (17 de julio de 1861), con el cual cancelaba «por el término de dos años todos los pagos, incluso el de las asignaciones destinadas para la deuda contraída en Londres y para las convenciones extranjeras ${ }^{3}$. El rechazo de los gobiernos de Inglaterra y Francia a dicha disposición fue inmediato; y a ello se sumó el gobierno español. Como consecuencia, el 31 de octubre se firmó, en Londres, la Convención Tripartita, que implicaba el envío de «fuerzas de mar y tierra combinadas» al territorio mexicano para obligarlo al pago de sus adeudos $^{3}$.

El tifo es una enfermedad que dio muchos problemas en México a lo largo de su historia. Está causada por una bacteria muy particular de la familia de las rickettsias descubierta justamente en México por el doctor Howard Taylor Ricketts durante la epidemia de 1909 (Fig. 1), que le causara la muerte por la enfermedad que estudiaba en mayo de $1910^{4}$. La bacteria es transmitida por los piojos infectados que excretan el microorganismo en las heces, y que es introducido en la herida dejada por el insecto cuando la persona se rasca como consecuencia del piquete.

La palabra «tifo» deriva del griego typhus, que significa "estupor». Es una enfermedad infecciosa causada por bacterias como Rickettsia typhi o Rickettsia prowazekii, que frecuentemente se confunde con la fiebre tifoidea causada por otra bacteria, Salmonella typhi. En ese tiempo existía tal confusión y muchas veces los pacientes eran mal diagnosticados, hasta que el Dr. Jiménez lo dejó claro, como se menciona más adelante.

No es difícil imaginar el escenario en el país para que se dieran dichas epidemias: el hacinamiento, la pobreza y la escasez de recursos hídricos e higiénicos hacían que la enfermedad se expandiera de manera importante. Como se ha mencionado, estas eran, en gran medida, las condiciones que imperaban en el país aun antes de la llegada de los franceses, la cual se agudizó en el periodo intervencionista.

El avance de las epidemias se pudo haber agravado tal vez por el caos natural causado, administrativamente, por las Leyes de Reforma; por ejemplo, en febrero de 1861 el presidente Juárez decretó la secularización de los hospitales y de los establecimientos de beneficencia, que habían sido manejados por el clero católico hasta entonces, y al mismo tiempo, para ordenar dichos servicios, ya en manos del Estado, creó la Dirección General de Fondos de la Beneficencia Pública, dependencia de la Secretaría de Gobernación. Entre las instituciones que pasaron al control de dicha dirección se encontraban el Hospital del Divino Salvador y la Casa de cuna para niños expósitos, y muchas otras instituciones hospitalarias y de asistencia, que bien o mal eran administradas con experiencia por el clero ${ }^{5}$. 


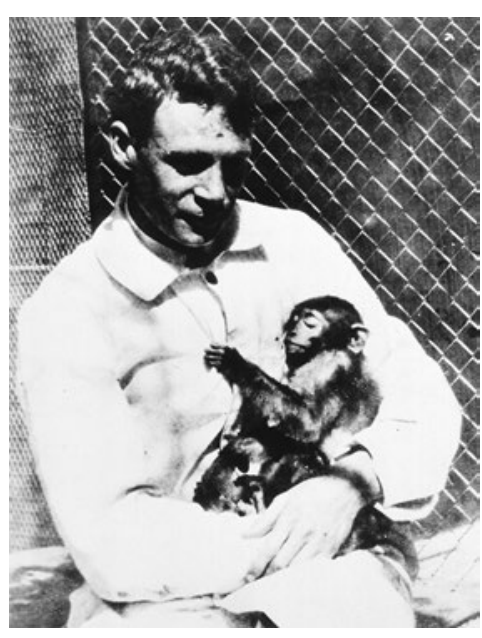

Figura 1. Fotografía del doctor Howard Taylor Ricketts con uno de sus animales de experimentación (The National Library of Medicine, $\mathrm{NIH}$ ).

La relación que existe entre la falta de recursos económicos y el desarrollo de la enfermedad puede tener, tal vez, como ejemplo máximo, el propio contagio y la muerte del general Ignacio Zaragoza.

Tanto en la Ciudad de México como en Puebla se presentaron casos de tifo en 1848 y continuaron en 1849. La enfermedad se extendió de 1857, año en que fue publicada la Constitución Liberal, siendo presidente de la República Ignacio Comonfort, a 1859. Lo mismo sucedió en 1861, 1862 (año de la Batalla del 5 de mayo) y 1867 (año de la Batalla del 2 de abril), como consecuencia de «los movimientos de grupos militares y civiles en condiciones de insuficientes medios higiénicos", lo que afectó a las tropas mexicanas victoriosas en Puebla. No solo el general Ignacio Zaragoza, sino también «muchos de sus soldados» ${ }^{6}$ y oficiales murieron víctimas del tifo.

Después del triunfo del Ejército de Oriente sobre los franceses, la comunicación entre el general Zaragoza y el presidente Juárez era constante; no había telegrama en que el general Zaragoza no le solicitara recursos económicos para el sostenimiento del ejército, no solo en términos de alimentación, sino también para la atención de enfermedades endémicas que atacaban, además de al ejército invasor, al nacional mismo.

Los habitantes de la ciudad de Puebla, lejos de cooperar, representaron cierto obstáculo. Tanto es así que el mismo general Zaragoza reporta el 9 de mayo: «esta ciudad execrable que no he incendiado porque existen en ella criaturas inocentes... En cuanto al dinero nada se puede hacer aquí, porque esta gente es mala en lo general y sobre todo muy indolente y egoísta... Qué bueno sería quemar Puebla. Está de luto por el acontecimiento del día 5. Esto es triste decirlo, pero es una realidad lamentable»7. Terrible el parte que rinde el general sobre la actitud de los habitantes de la heroica Puebla.

El primero de septiembre de 1862, el general Zaragoza empezó con los síntomas de la infección, particularmente fiebre elevada, por lo que fue enviado a su cuartel en Puebla. Meses antes había recibido la visita de su hija, y su esposa había fallecido a principios de ese mismo año, a quien solo le pudo proporcionar 100 pesos para su manutención, suficiente para 3 días, lo que puede evidenciar la situación económica del general y, por ende, de todo el Ejército de Oriente. Ignacio Zaragoza falleció el 8 de septiembre de 1862, a la edad de 33 años, como consecuencias de una rickettsiosis o tifo ${ }^{7}$, truncando una carrera brillante del general, que sin duda pudo haber dado aún mucho más a la nación.

«El gobierno [federal] considera la muerte inopinada del general Zaragoza como una desgracia pública», escribió Enrique de Wagner, ministro de Prusia en México. «Después de algunos días de enfermedad, Zaragoza murió de tifo en Puebla, donde esta epidemia hace enormes estragos, así como en toda la zona que va desde esta ciudad a Orizaba." El diplomático prusiano advirtió que el ejército francés se expondría "a grandes peligros en caso de tomar la ruta de todos estos pueblos y ciudades infestadas", y recomendó «que se hiciera pasar el grueso de las fuerzas por Jalapa y Perote, Huamantla, Otumba o San Martín", quedando protegida la ciudad de Puebla «por algunos miles de hombres»".

Es interesante que las rickettsiosis sean una constante en los procesos bélicos. Se sabe que en la guerra civil española de 1480-1490 las tropas de cristianos y moros se diezmaron por causa de la enfermedad, mientras que efectos similares fueron causados en las tropas de Napoleón en 1812, mientras que en la Primera Guerra Mundial se presentaron alrededor de 100,000 casos en 1914 y 150,000 en 1916 ${ }^{\circ}$. La enfermedad fue también clave en los planes de eliminación de judíos en los países controlados por la Alemania nazi, aspecto tratado magistralmente en el trabajo de la Dra. Naomi Baumslag ${ }^{4}$.

\section{La fiebre amarilla}

La fiebre amarilla es una enfermedad causada por un virus de la familia arbovirus del género Flavivirus, y es transmitida por mosquitos infectados, como Aedes aegypti (Fig. 2). La enfermedad se caracteriza 


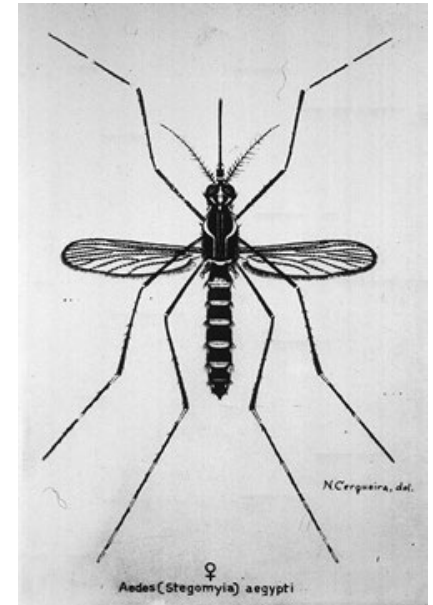

Figura 2. Representación clásica de un mosquito Aedes (Stegomyia) aegypti (The National Library of Medicine, NIH).

por fiebres elevadas y un daño grave al hígado, generando ictericia en los pacientes, y de ahí el término «fiebre amarilla». Una vez más, la falta de saneamiento en los depósitos de agua contaminada es fundamental para la reproducción del mosquito. La enfermedad está relativamente controlada en la actualidad, gracias a las vacunas y los tratamientos efectivos, pero en tiempos de la invasión francesa esto no era ni imaginado.

La fiebre amarilla, o vómito negro, era algo que preocupaba mucho a los ejércitos invasores. Uno de los primeros reportes sobre el también llamado vómito prieto lo refiere Jena-Jacques Ampère ${ }^{10}$ al referir que en México hay dos cosas totalmente insufribles: «la fièvre jaune et les brigands». El reporte de Ampère es contundente: "uno de los peores inconvenientes (es la fiebre amarilla)»"11.

Los españoles que habían llegado primero a las costas del Golfo de México fueron las primeras víctimas de ese mal, endémico de esa región. El general Juan Prim, comandante español, envió unas semanas después de atracar alrededor de 800 soldados a hospitales en Cuba para su atención. Tal vez el presidente Juárez aprovechó esa "defensa natural» contra los invasores y jugó con el tiempo de negociación, esperando que la enfermedad fuera un aliado natural.

La negociación generó que se permitiera a los invasores avanzar hacia Orizaba, ubicada a 2800 metros sobre el nivel del mar, donde difícilmente el mosquito subsistía. Los españoles e ingleses, al percatarse de las intenciones francesas, se retiraron y embarcaron de regreso a sus países, pero como se ha mencionado, no así los franceses.
Gloria Grajales publicó en 1963, en la revista Historia Mexicana, las citas de documentos del archivo referente a la intervención en México de Inglaterra, Francia y España que se conservan en la Public Record Office en Londres. Particularmente cita aquellos relativos a la intervención francesa (clasificación F.O. 97/278, Vol. I, y 97/279, Vol. II, con el título French Expedition $)^{12}$. En dicho reporte pueden leerse al menos tres entradas haciendo referencia a la fiebre amarilla y a las dificultades que tuvieron los franceses para lidiar con dicho problema. La primera referencia, sin fecha, pero reportada alrededor de agosto de 1862 dice: "Sin fecha - Llegada de 300 marinos en la fragata Ifigenia; contagio de fiebre amarilla en Veracruz» (F.O. 97/278, I, f. 97). Más tarde se refiere: «4 de diciembre de 1862 - Johnson al conde Russell (No. 1347): Sobre mortalidad entre las tropas francesas a causa de la fiebre amarilla; alistamiento de mil negros egipcios para servir en las fuerzas expedicionarias de México (F.O. 97/278, I, f. 187). Y luego: París, 6 de enero de 1863 - Johnson al conde Russell (No. 20, confidencial): Sobre los posibles motivos para enviar refuerzos a México, cubrir bajas por enfermedad y muerte (1500 soldados y 62 oficiales muertos). Información confidencial obtenida a través del capitán Hore. Medidas tomadas por el gobierno francés para sufragar los gastos de la expedición, etc." (F.O. 97/278, I, ff. 213-214). «Memorándum anexo al documento anterior: Datos obtenidos a través del señor Xavier Raymond sobre el estado del ejército francés en México. Fuertes bajas por la fiebre amarilla y otras enfermedades. Mal estado de los caminos, necesidad de transporte para la expedición a Tampico. Los gastos mensuales para transporte terrestre en México resultan insuficientes. Raymond piensa que el sentimiento contra la expedición es unánime, etc." (F.O. 97/278, I, ff. 216-218).

Es muy claro que el ejército francés se veía diezmado sensiblemente por bajas y muertes por la fiebre amarilla, pero la información se mantenía confidencial, tal vez con el ánimo de no aumentar aires victoriosos en las tropas mexicanas. La fiebre amarilla, si bien afectó a los invasores, no fue motivo, al final, para que cumplieran su objetivo, al menos temporalmente.

\section{Veracruz, Maximiliano y la fiebre amarilla}

"Veracruz es una ciudad sucia y estrecha que tiene mala fama por su terrible clima y formidable calor", afirmó el conde Carl Khevenhüller-Metsch, integrante 
del cuerpo de voluntarios austriacos que llegó a México para acompañar a Maximiliano de Habsburgo. Después de 3 semanas de viaje en el navío Floride, más de 800 hombres arribaron al puerto veracruzano el 7 de diciembre de 1864, en donde tuvieron que soportar $44{ }^{\circ} \mathrm{C}$ durante la noche. Khevenhüller conoció "a médicos alemanes y austriacos a quienes hay que rendir los mayores elogios por su abnegación en los tiempos de la fiebre amarilla, esta enfermedad terrible que arrebata al cabo de pocas horas»13. Al siguiente día continuaron su viaje a la capital del país, ante el temor de contagio dadas las condiciones insalubres del puerto.

El sábado 28 de mayo de 1863 ancló, en el puerto de Veracruz, el navío Novara, en el cual arribaron Maximiliano de Habsburgo, su esposa Carlota de Bélgica y su corte. A las $4 \mathrm{~h}$ de la mañana del domingo 29 todo se alistó «para continuar de inmediato el viaje hacia la capital, porque una estancia prolongada en Veracruz no era recomendable, debido a la fiebre amarilla reinante en esa ciudad, que dicen que es sobre todo peligrosa para los recién llegados ${ }^{14}$, afirmó Wilhelm Knechtel, botánico oficial del emperador. Sin embargo, 2 años después, el emperador enfermaría, requiriendo la atención de un especialista mexicano para tratarse.

Maximiliano se encontraba «afectado del hígado y además venía sufriendo de fiebres intermitentes, contraídas en uno de los viajes a la tierra caliente ${ }^{15}$. Friedrich Semmeleder, médico de cabecera del austriaco, no conociendo «muy bien el tratamiento especial para [dichas] fiebres intermitentes", propuso que el emperador «consultara con alguno de los médicos mexicanos que conocían perfectamente el tratamiento" contra ellas. Fue atendido por el médico Rafael Lucio, "que ya en esa época era una eminencia». Inicialmente Lucio se había resistido a ello por ser «un liberal acérrimo y completamente opuesto al régimen imperial». Antes de salir a Cuernavaca, Maximiliano quiso «saldar su cuenta con su doctor mexicano, [...] pero el sabio doctor rehusó del todo recibir ni un solo peso, alegando que le bastaba haberse conquistado la gratitud del Soberano $»^{14}$.

Durante el siglo XIX, los brotes epidémicos de fiebre amarilla, tifo, cólera, sarampión, peste y viruela sumaron más de 70 en el Estado de Veracruz. Las enfermedades atacaron tanto las ciudades como las pequeñas poblaciones, diezmando no pocas de ellas. Aunque las epidemias de fiebre amarilla fueron de las más frecuentes, «los decesos eran cuantitativamente menores que la viruela». Después de 1826 y 1855, en un quinquenio se presentaron tres epidemias de fiebre amarilla: 1842, 1843 y 1847, esta última el año de la intervención norteamericana. Entre 1850 y 1852 se dio otro brote de la enfermedad, lo mismo que durante la intervención francesa en 1863 y 1867. «La salubridad en el territorio veracruzano [como en otras regiones del país] iba de la mano con el clima y con las luchas internas e internacionales en defensa de la soberanía»16.

\section{Estado de la medicina durante la intervención francesa}

Es irónico que la existencia de múltiples epidemias (en 1864 la esperanza de vida del mexicano se estimaba en 30 años $)^{5}$ estuviera acompañada de eventos fundamentales en la historia de la medicina en el periodo que estuvo ocupado el país por Francia (1862 a 1867).

El 19 de abril de 1864 se funda la Comisión Científica, Literaria y Artística de México, y el día 30 del mismo mes se lleva a cabo la primera reunión de la Sección de Ciencias Médicas (más tarde Academia Nacional de Medicina). La sección estuvo dividida en cinco subsecciones: patología, higiene, medicina legal y estadística médica, medicina veterinaria, materia médica y farmacología, y fisiología y antropología. La presidencia estuvo en manos del doctor Carlos Alberto Ehrmann, y la vicepresidencia recayó en el doctor Miguel Francisco Jiménez, profesor de la Escuela Nacional de Medicina. Entre otros notables médicos de la época que pertenecieron a la sección se puede mencionar al Dr. Rafael Lucio y al Dr. José María Vértiz ${ }^{17}$. Como se ha mencionado, esta época es sin duda una de las más grandes en cuanto a médicos y científicos ejemplares; aunado a los anteriores se puede mencionar a los doctores Lauro Jiménez y Leopoldo Río de la Loza, haciendo aportes importantes en farmacología, entre otros.

Uno de los principales logros que tuvo la sección médica fue la publicación de la Gaceta Médica de México, periódico de la sección médica de la comisión científica, que después simplemente sería Gaceta Médica de México, como hasta en la actualidad se llama. El primer número salió a la luz el jueves 15 de septiembre de 1864, siendo su primer presidente el Dr. Miguel Francisco Jiménez.

En el primer número, justo se discute sobre las diferencias entre el tifo o tabardillo y la fiebre tifoidea, escrito por el mismo Dr. Jiménez, haciendo mención 
de ser una enfermedad endémica del país y dejando clara su importancia.

\section{El Dr. Miguel Francisco Jiménez, el absceso hepático amebiano y la medicina mexicana científica}

El Dr. Miguel Francisco Jiménez (Fig. 3) representa un ejemplo de la creciente ciencia médica en el México del Imperio. Era un hombre inteligente y culto, que empujó fuertemente la medicina racional y científica, tomando como base la observación y no la adivinación; fuerte seguidor de los aportes de Auenbrugger y de Laennec, sin duda un médico adelantado a su tiempo, aplicando una visión científica en la propedéutica clínica y a todo el ejercicio de la medicina.

Nació en Amozoc, Puebla, en 1813. Terminó sus estudios de medicina en 1838 en el Establecimiento de Ciencias Médicas y ocupó casi de inmediato el puesto de profesor de patología y posteriormente de anatomía, cátedra que ofreció hasta su muerte ${ }^{18}$.

Además de los estudios que llevó a cabo para distinguir entre tifo y fiebre tifoidea, realizó investigación sobre otra enfermedad que aquejó mucho a la población del país, el absceso hepático amebiano, la cual se presentaba con mucha frecuencia en México, incluso desde el siglo XVI.

El absceso hepático amebiano es la acumulación de pus en el hígado en respuesta a la presencia de Entamoeba histolytica. La enfermedad se adquiere por la ingestión de agua o alimentos contaminados con materia fecal. Una vez más, la alta incidencia de esta enfermedad nos habla de hacinamiento, pobreza y malas condiciones sanitarias en aquella época. Los pacientes con la enfermedad morían con regularidad, aun por intervenciones médicas desafortunadas en las que usaban un cuchillo de navaja falciforme, sin anestesia y sin asepsia, para el tratamiento, no solo para el absceso hepático, si no para cualquier tipo de absceso. Si el paciente no moría por la enfermedad, con seguridad moría por la infección. Esto era común hasta el avance que propuso el Dr. Jiménez de intervenir quirúrgicamente, por punción evacuadora, para drenar el absceso, con lo que se evitaba su rompimiento y diseminación a otros órganos. No es difícil imaginar que dicho procedimiento salvó vidas e hizo que los pacientes con la enfermedad tuvieran un mejor pronóstico ${ }^{19}$.

El alto nivel profesional y científico del Dr. Jiménez le mereció el reconocimiento de Maximiliano de

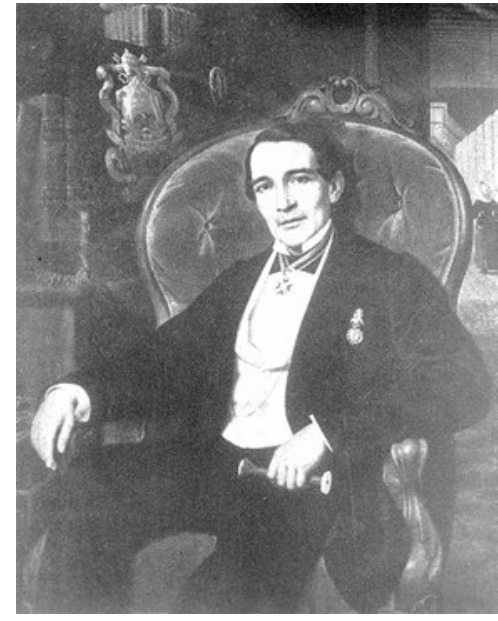

Figura 3. El doctor Miguel Francisco Jiménez.

Habsburgo, quien lo incorporó como uno de sus médicos personales, junto con los doctores Federico Semeleder, Samuel Basch y Rafael Lucio Nájera.

El Dr. Jiménez realmente pensaba que la llegada del Imperio era algo bueno para el país, no en el plano de exacerbación conservadora o apología de la monarquía, sino que pensaba que se podría establecer un nuevo orden nacional que hiciera transitar al país hacia una mejor calidad de vida. En una carta que envía a José María Iglesias menciona: «tengo fe de que podría fundarse un orden que, realmente aceptado por todos, acabaría para siempre con la eterna anarquía que nos consume». El Dr. Jiménez murió en la Ciudad de México en 1876.

\section{Conclusión}

El periodo de la intervención francesa ha sido una de las épocas más convulsivas para la nación, ya que más allá del conflicto armado y de la ocupación se vivió un desastre económico, político y social, generando que muchos de los problemas de salud pública se exacerbaran afectando a propios y extraños, como se ha visto. Sin embargo, es también esta época la que marca el inicio de la revolución en la ciencia médica en nuestro país por médicos notables, que si bien no se han mencionados todos, se ha tomado como ejemplo al Dr. Francisco Jiménez como representante fiel de esa generación de médicos mexicanos, interesantemente, formados en la escuela francesa de medicina. Finalmente, también fue en ese periodo (el jueves 15 de septiembre de 1864) el inicio de la publicación de la Gaceta Médica de México. 


\section{Agradecimientos}

El trabajo ha sido escrito con fines de difusión y divulgación, y contó con el apoyo del CONACYT Ciencia Básica No. 252942, Fronteras de la Ciencia 2015 No. 1320, el Instituto Estatal de Documentación del Estado de Morelos y la Universidad Autónoma Metropolitana Iztapalapa.

\section{Bibliografía}

1. Gonzales Lezama R. Del triunfo republicano a la crisis política de 1861 . El peor año de la república. Relatos e Historias en México. 2012;45:48-54

2. Zaragoza I. Parte de Guerra del General Zaragoza. Relatos e Historias en México. 2012;4:68.

3. Porte Petit JM. Antecedentes de la intervención. Primer Congreso Nacional de Historia para el Estudio de la Guerra de Intervención, 1963. Sociedad Mexicana de Geografía y Estadística; 1963.

4. Baumslag N. Medicina asesina. Médicos nazis, experimentación con humanos y tifus. Barcelona: Plataforma Editorial; 2014.

5. Concheiro AA. Cronología médica mexicana. Cinco siglos. México: Siglo $\mathrm{XXI} ; 2010$.

6. Florescano E, Malvido E. Ensayos sobre la historia de las epidemias en México. Vol. 1. Instituto Mexicano del Seguro Social; 1982.
7. Rosas A. El patriotismo de Ignacio Zaragoza. Paisaje de la batalla. Relatos e Historias en México. 2012;45:71-6.

8. Díaz L. Versión francesa de México. Informes diplomáticos. 1862-1864. Vol. 3. El Colegio de México; 1965.

9. Peterson RKD. Insects, disease, and military history. The Napoleonic campaigns and historical perception. American Entomologist. 1995;41:147-61.

10. Ampère JJ. Promenade en Amérique. Etats-Unis-Cuba-Mexique. 2 ed. Vol. II. Paris: Michel Levy Freres; 1860

11. Helguera MM. Posibles antecedentes de la intervención francesa. Historia Mexicana. 1965;15:1-24.

12. Grajales G. Intervención francesa y segundo imperio. Historia Mexicana. 1963;13:284-316.

13. Hamann B. Con Maximiliano en México: del diario del príncipe Carl Khevenhüller, 1864-1867. México: FCE; 1992.

14. Knechtel W. Las memorias del jardinero de Maximiliano. Apuntes manuscritos de mis impresiones y experiencias personales en México entre 1864 y 1867. México: Instituto Nacional de Antropología e Historia; 2012.

15. Blasio JL. Maximiliano íntimo. El emperador Maximiliano y su corte. Memorias de un secretario particular. México: Librería de la Vda. de C. Bouret; 1905.

16. Aguilar Sánchez M, Ortiz Escamilla J. Historia general de Veracruz. México: Gobierno del Estado de Veracruz; 2011.

17. Rodríguez Pérez ME. De la Sección Médica a la Academia de Medicina de México: 1864-1880. En: La Academia Nacional de Medicina de México. 150 años de actividad ininterrumpida. México: Intersistemas editores, CONACYT; 2014.

18. Martínez Guzmán M. Cuatro médicos personales del emperador Maximiliano de Habsburgo. 1864-1867. Boletín Mexicano de Historia y Filosofía de la Medicina. 2003:6:17-22.

19. Fernández del Castillo F. El tratamiento de los abscesos hepáticos antes del doctor Miguel Francisco Jiménez. Gac Med Mex. 1957;87:395-410. 